\title{
REFLEXÕES SOBRE A POLÍTICA SOCIAL E A POLÍTICA DE LAZER NO BRASIL
}

\author{
Recebido em: $15 / 02 / 2016$ \\ Aceito em: 19/08/2016 \\ Tarcila Betas Lopes \\ Prefeitura Municipal de Belo Horizonte \\ Belo Horizonte - MG - Brasil \\ Dalva de Cássia Sampaio dos Santos \\ Prefeitura Municipal de Belém \\ Secretaria de Educação do Estado do Pará \\ Belém - PA - Brasil \\ Hélder Ferreira Isayama \\ Universidade Federal de Minas Gerais \\ Belo Horizonte - MG - Brasil
}

RESUMO: É a partir da Constituição Brasileira de 1988 que o lazer passa a integrar o rol de direitos sociais, no entanto, o tema é tratado como conteúdo das políticas públicas, desde a década de 1930, juntamente com a tentativa de instituição de um Estado de Bem estar Social Brasileiro. Nesse contexto, o objetivo deste texto é discutir e analisar o lazer como direito social no Brasil tendo como referência três períodos de inovação e produção legislativa na área social (1930 a 1964; 1964 a 1985 e 1985 até os dias atuais).

PALAVRAS CHAVE: Atividades de Lazer. Políticas Públicas. Política Social.

\section{ANALISIS ON SOCIAL POLICY AND LEISURE POLICY IN BRAZIL}

ABSTRACT: The Brazilian Constitution of 1988 turned leisure one of the social rights. This subject has been treated as contents of public policies since the 1930s, along with the attempt to impose the Welfare State Brazilian. In this context, the aim of this paper is to analyze the leisure and social rights in Brazil with reference to three periods of innovation and legislative production in the social area (1930-1964, 1964-1985 and 1985 to the present day).

KEYWORDS: Leisure Activities. Public Policies. Social Policy. 


\section{Introdução}

Compreendendo a política pública como o "Estado em ação" nos interessa um tipo particular de política, a política social. Para Zauli (2005) essa ideia de política está centrada no princípio de justiça, proteção social e pode contribuir na diminuição de desigualdades geradas pelo processo de desenvolvimento econômico. Portanto, essa visão somada a possibilidade de igualdade de oportunidades procura eliminar as discriminações, proteger os "fracos" e criar outros direitos sociais.

Nesse contexto, o lazer, foco desse texto, é considerado legalmente um direito social a partir da Constituição de 1988 embora já venha sendo tratado como conteúdo de políticas governamentais desde a época de 1930, data que também marca a tentativa de se constituir um Estado Bem Estar Social no Brasil. A partir de 1930 a política social se consolida na agenda de intervenção do Estado com a edificação de um sistema institucional público de proteção social.

Para tanto, adotamos, como referência, três períodos férteis em inovações e na produção legislativa na área social: de 1930 a 1964 - fase de introdução e expansão fragmentada do Estado Social; de 1964 a 1985 - fase de consolidação institucional e de reestruturação conservadora e a partir de 1985 - fase de reestruturação progressista (DRAIBE, 1993). Traçando um paralelo com o cenário político de cada época, com a organização institucional e com políticas de lazer desenvolvidas no âmbito federal buscaremos responder ao seguinte questionamento: é possível interpretar o lazer como direito social no Brasil? Essa questão suscita e orienta a construção desse texto. 


\section{Os Direitos Sociais e a Constituição dos Estados de Bem-Estar-Social}

O tema "direito social" tem sido debatido nas sociedades contemporâneas e tornouse pauta de discussão sendo recorrente à utilização de termos como promoção de cidadania e inclusão social para justificar as mais diversas formas de atuação tanto no setor público quanto no privado. $\mathrm{O}$ emprego desses termos com variadas configurações expressa implicitamente, ou mesmo explicitamente, interesses e concepções de mundo e estes não necessariamente promoverão uma sociedade mais justa e igualitária. $\mathrm{O}$ fato é que o Brasil apresenta, desde a época de seu descobrimento, um quadro de desigualdade e exploração que se tornou, segundo Carvalho (2015), o câncer da atualidade, de resolução complexa, porém urgente.

No século XVIII, a penetração do sistema de produção capitalista em uma estrutura social tradicional, marcada pelo domínio de grandes latifundiários, provocou uma rearticulação entre identidades pessoais e coletivas (REIS, 2000). A desigualdade e a hierarquia, que caracterizavam à organização societária da época, foram corroídas pelo princípio igualitário de mercado. Para que as livres trocas mercantis fluíssem, como ditava o sistema, promoveram-se os direitos individuais. De acordo com os ideais liberais, todos são considerados proprietários, uns possuem mão de obra e outros equipamentos e máquinas. Interferir na possível ordem de troca que pode acontecer entre trabalhadores e proprietários de máquinas significava ferir a autonomia e a liberdade do indivíduo. Como enfatiza Coutinho (1989), a ajuda e tutela do Estado aos mais fracos significava uma 
violação dos critérios de seletividade ${ }^{1}$ do Estado liberal que propunha o controle mínimo das relações no âmbito do mercado. Cabia, portanto ao poder público assegurar e fazer cumprir os direitos civis. É esse Estado liberal restrito que, segundo Coutinho (1989, p. 51), Marx combateu identificando-o "[...] como comitê executivo para gerir os negócios da burguesia" uma vez que a participação na vida política da sociedade era restrita aos proprietários dos meios de produção e de terra não incluindo nesse caso a força de trabalho.

Entretanto, como ressalta Reis (2000) esse mesmo sistema que desgasta as formas tradicionais e hierárquicas de poder consolidadas apresenta-se fundamentado na desigualdade social e na dominação explícita pela sociedade de classes. A busca incessante pelo lucro gera inegáveis externalidades como jornadas de trabalho de 12 a 15 horas e exploração da mão de obra infantil. Como as condições básicas de sobrevivência dependiam inteiramente das relações monetárias travadas no âmbito do mercado, a exploração e a desigualdade acendem o conflito por igualdade e justiça social.

Como ressalta Behring e Boschetti (2007),

[...] o enfraquecimento das bases materiais e subjetivas de sustentação dos argumentos liberais ocorreu como [...] resultado de alguns processos políticos dos quais vale destacar dois: o crescimento do movimento operário e a concentração e monopolização do capital, demolindo a utopia liberal do indivíduo empreendedor orientado por sentimentos morais ( $\mathrm{p}$. $67)$.

A maioria trabalhadora descontente com as disparidades sociais produzidas questiona o modelo de produção e por meio da organização em partidos e sindicatos de massa reivindicam, entre outras causas, a extensão do direito de voto e a redução da jornada

\footnotetext{
${ }^{1} \mathrm{O}$ conceito de seletividade estrutural foi desenvolvido por Claus Offe e publicado no livro chamado "Problemas Estruturais do Estado Capitalista" de 1984. Para o autor referido, a natureza de classe de um Estado é definida pelos seus critérios de seletividade, ou seja, pela seleção do que deve e do que não deve se constituir objeto de política pública.
} 
de trabalho, ou seja, a abertura do Estado aos interesses da classe trabalhadora.

Diante da pressão e do risco eminente da revolução, para que o modo de produção vigente continuasse legitimado pelos setores populares a classe burguesa faz concessões e o Estado é obrigado a rever sua pauta de seletividade com vistas a promover o bem-estar social. Entretanto pela característica do próprio sistema de produção, o limite de concessões se estabelece a tal ponto que não comprometa a reprodução do capital global. Essas conquistas políticas e sociais, segundo Coutinho (1989, p. 54), “[...] são importantes porque indicam a possibilidade de, num Estado capitalista, ter lugar a representação de interesses das classes subalternas, com a consequente formulação de políticas que respondam a demandas provenientes dessas classes".

Novos atores entram em cena, o jogo não é mais de soma zero, e na arena política o embate e a negociação entre trabalhadores e proprietários se funda. É nesse cenário que emerge o Estado de Bem-Estar-Social ${ }^{2}$ a partir do desenvolvimento sócio-econômico retratado pela industrialização e urbanização no contexto da produção, da dialética mobilização e pressão das classes populares e do desenvolvimento político-institucional com a extensão do sufrágio. Estas questões, ao mesmo tempo em que explicam à emergência do Welfare State, servem de parâmetro para diferenciá-los dentre suas diferentes formas de organização.

Segundo Draibe (1993, p.5) “[...] o conceito de Welfare State não é unívoco e admite variações segundo as correntes teóricas a que se filiam seus estudos" diversificando

\footnotetext{
${ }^{2}$ De acordo com Medeiros (2001) existem controvérsias em torno do significado dos termos utilizados para nomear o Estado Social. Embora essa distinção seja relevante, para fins desse estudo ela não é realizada e os termos Estado de Bem-Estar-Social, Welfare State e Estado Social são utilizados como sinônimos.
} 
as concepções de como, com que peso e grau deve o Estado atuar na área social. Portanto, num esforço de significação assinalam-se os elementos comuns presentes nessas diferentes concepções e que de alguma forma compõem uma delimitação conceitual de Estado Social. Num primeiro momento é consensual a existência de ação estatal na organização e implementação das políticas sociais. No segundo momento, concebe-se a existência de uma relação entre Estado e mercado onde o primeiro tende a alterar o livre movimento assim como os resultados adversos produzidos pelo segundo. Por fim, localiza-se a noção da substituição temporária ou permanente de renda ou mesmo a manutenção da mesma tomando como referência um patamar mínimo considerado necessário para a satisfação das necessidades básicas do indivíduo.

Fundamentando-se assim no conceito proposto por Draibe (1990, p.3) entendemos por Welfare State "[...] no âmbito do Estado capitalista, uma particular forma de regulação social que se expressa pela transformação das relações entre o Estado e a economia, entre o Estado e a sociedade, a um dado momento do desenvolvimento econômico". Estas transformações são expressas por meio da oferta e da regulação de serviços públicos de educação, saúde, previdência social, integração e substituição de renda, assistência social e habitação que amenizam tensões e potencializam a produção.

Concretamente, trata-se de processos que, uma vez transformada a própria estrutura do Estado, expressam-se na organização e produção de bens e serviços coletivos, na montagem de esquemas de transferências sociais, na interferência pública sobre a estrutura de oportunidades de acesso a bens e serviços públicos e privados e, finalmente, na regulação da produção e distribuição de bens e serviços sociais privados (DRAIBE, 1990, p. 3).

É esse Estado Social que promoverá as políticas sociais caracterizadas como estratégia governamental para intervenção nas relações sociais por meio da alocação e 
distribuição de valores. Implica em escolhas em um quadro conflitivo de forças e interesses e pressupõem um posicionamento do que é obrigação do Estado ou não. Para Santos (1987, p. 37) toda política social é uma escolha trágica que segue à um princípio de justiça consistente e coerente. "O problema da política social transforma-se no desafio de encontrar um princípio de justiça coerente e consistente que seja superior a qualquer outro".

Apesar da formação em nível mundial de uma tendência estruturante de Estado, a constituição dos Welfare State no ocidente variou, segundo Draibe (1993), de acordo com as especificidades históricas e políticas progressistas ou conservadoras de cada país assim como as concepções de igualdade e justiça que alimentavam. Tais especificidades se referem às complexas dimensões da proteção social que tangem as relações de inclusão/exclusão, os aspectos redistributivos e as relações com o sistema político.

São apontadas, por Draibe (1990), três diferentes composições de Estados de BemEstar-Social, a saber: residual, meritocrático-particularista e institucional- redistributivista. No tipo residual, intervém-se somente quando os canais naturais de satisfação das necessidades (esforço individual, família e mercado) revelam-se insatisfatórios. A assistência é dada emergencialmente aos comprovadamente pobres e a consequência, segundo Esping-Andersen é que:

[...] esse tipo de regime minimiza os efeitos da desmercadorização, contém efetivamente o domínio dos direitos sociais e edifica uma ordem de estratificação que é uma mistura de igualdade relativa da pobreza entre os beneficiários do Estado, serviços diferenciados pelo mercado entre as maiorias e um dualismo político de classe entre ambas as camadas sociais. Os exemplos arquétipos deste modelo são os Estados Unidos, o Canadá e a Austrália (1991, p. 108).

Para a tipologia meritocrática-particularista cada um deve resolver suas próprias questões com base no seu trabalho reconhecendo, portanto a necessidade da intervenção 
estatal para corrigir parcialmente as distorções. Apresenta-se como um sistema estratificado no qual os direitos estão ligados à classe, ao status. "De outra parte, a ênfase estatal na manutenção das diferenças de status significa que seu impacto em termos de redistribuição é desprezível” (ESPING-ANDERSEN, 1991, p. 109) já que os benefícios sociais eram concedidos aos inseridos no mercado tendo como referência a categoria profissional da qual pertencia o cidadão. Aquela parcela excluída das relações legais de trabalho ficava a mercê da misericórdia de instituições como a Igreja Católica. Essa tipologia específica fundamentou a constituição dos Estados Sociais na França, Alemanha e Itália.

Por fim, o tipo social-democrata era voltado para a produção e distribuição de bens e serviços sociais, extra mercado garantidos a todos os cidadãos de forma universal. Visava-se a promoção da igualdade com melhores padrões de qualidade o que implicava que

[...] os serviços fossem elevados a níveis compatíveis até mesmo com o gasto mais refinado das novas classes médias e em segundo lugar que a igualdade fosse concedida garantindo-se aos trabalhadores plena participação na qualidade dos direitos desfrutados pelos mais ricos (ESPING-ANDERSEN, 1991, p. 109).

Foi a tipologia que caracterizava o Estado Social adotado nos países escandinavos.

Para Medeiros (2001, p. 8), “[...] as circunstâncias do surgimento e do desenvolvimento do Welfare State no Brasil são peculiares e diferentes das observadas nos países aos quais as teorias mencionadas se referem". Foi desenvolvido e consolidado num país de capitalismo tardio, sob a égide do sistema autoritário seguindo um modelo concentrador e socialmente excludente de desenvolvimento econômico.

Considerando tais especificidades e corroborando com Draibe (1993, p.4) tomamos 
o caso brasileiro como um dos padrões de Estado Social dentre os vários desenvolvidos. Isso "[...] significa reter e amalgamar características de tendências gerais às condições históricas particulares do Brasil”. Nesse sentido, consideramos plausível afirmar que as políticas de intervenção do Estado na sociedade, que ocorreram no Brasil a partir da década de 30, nos permitem concluir sob a constituição do nosso Welfare State, embora tenha se estruturado sob um padrão particular de sociedade (de capitalismo tardio, autoritário, concentrador e socialmente excludente).

\section{A Introdução do Estado Social Brasileiro (1930-1964) e os Reflexos nas Políticas de}

\section{Lazer}

No Brasil, a partir de 1930 ocorrem transformações no comportamento do Estado associadas à revolução da era Vargas. O Estado passa a intervir na esfera da acumulação reorganizando o processo de produção e promovendo uma regulação social acelerada. A era Vargas inaugurada com a revolução de 1930 incita transformações no âmbito de atuação do Estado. Implanta-se o grosso da legislação trabalhista e previdenciária incorporando novos atores sociais ao sistema político ainda que subordinados pela segmentação e regulação. Cabe, ressaltar que toda a legislação produzida foi introduzida em um ambiente de baixa ou nula participação política e de precária vigência dos direitos civis (CARVALHO, 2015).

Em 1931 acontece a criação do Ministério do Trabalho, Indústria e Comércio (MTIC) que reúne os meios materiais e humanos para execução e fiscalização da legislação trabalhista, previdenciária e sindical. É sob o controle desse ministério que tais políticas se materializam e ganham forma. $\mathrm{Na}$ área trabalhista, segundo Carvalho (2015), progressivamente foi se consolidando a codificação das leis que culminou na elaboração do 
Código de Leis Trabalhistas (CLT). Em 1932 regulamentou-se a jornada de trabalho de 8 horas no comércio e na indústria, o trabalho feminino infantil e foram criadas as comissões e juntas de conciliação e julgamento - esboço da justiça do trabalho. Já as férias regulamentares, o salário mínimo, as indenizações, o exercício regular da profissão e a criação da Justiça do Trabalho aconteceram com a Constituição de 1934.

A investida pública na previdência social iniciou com a criação dos Institutos de Aposentadoria e Pensão (IAP), instrumento de realização do projeto político de incorporação das classes trabalhadoras urbanas, que representam e assistem determinadas categorias profissionais. A primeira criação foi o Instituto de Aposentadoria dos Marítimos (IPAM) que aconteceu em 1933. O recurso destinado aos IAP's provinha do governo, dos patrões e dos trabalhadores e beneficiava somente os cidadãos enquadrados na estrutura sindical montada pelo governo. Dentre outros benefícios concediam aposentadoria por tempo de trabalho, auxílio médico-hospitalar e auxílio doença, morte e parto sendo que estes variavam de acordo com os diferentes institutos. Ressaltamos a exclusão dos trabalhadores autônomos, domésticos e rurais o que reforça a concepção da política social como privilégio dos trabalhadores institucionalizados e não como direito de todos (CARVALHO, 2015).

Foi esse o tema que inspirou Santos (1994, p. 75) a nomear a cidadania de regulada. Os direitos sociais eram conferidos somente aos grupos ocupacionais reconhecidos e regulamentados pelo Estado. "As raízes da cidadania não estavam em um código de valores políticos, mas sim em um sistema de estratificação ocupacional definido por norma legal. Os cidadãos eram aqueles localizados em ocupações reconhecidas e definidas por lei”. Nesse modelo, as políticas sociais reproduzem o sistema de desigualdade 
preexistente na sociedade onde benefícios diferenciados são concedidos para cidadãos estratificados em categorias profissionais.

Draibe (1990) considera importante assinalar que o sistema brasileiro de proteção social avançou na trilha de suplementar-se por mecanismos assistenciais que operavam de modo precário, uma vez que eram vagamente definidos, não institucionalizados, descontínuos, não garantidos e nunca avaliados. Essas ações tenderam sempre a tornaremse fértil campo para as práticas assistencialistas e clientelistas.

No que tange às ações públicas de lazer, destacamos que a Constituição de 1937 fixou o repouso do trabalhador os domingos e a licença remunerada após um ano de registro em carteira. A lei também sinaliza para a possibilidade de alteração da carga horária de trabalho diário, podendo este tempo ser reduzido (BRASIL, 1937).

Nesse contexto, Gomes (2003) afirma que o Ministério do Trabalho, Indústria e Comércio (MTIC) preocupado com riscos sociais como promiscuidade, alcoolismo, uso de drogas e ociosidade, provenientes da ampliação das horas de folga pela regulamentação da jornada de trabalho, assumiu o dever de preencher essas horas com atividades recreativoeducacionais.

A partir desse prisma de atuação, foi criado como setor do MTIC, por meio da portaria 68 de 06 de dezembro de 1943, o Serviço de Recreação Operária (SRO) que, em parceria com os sindicatos, encarregou-se de organizar e coordenar as diversas atividades culturais e esportivas tendo como público alvo os trabalhadores sindicalizados e suas famílias. Sua criação foi justificada pela necessidade de um espaço que pudesse organizar “os meios de recreação da classe operária, prestando aos sindicatos sua assistência e colaboração" (SUSSEKIND, 1946, p. 7). 
Para Brêtas (2010) o SRO teve cinco intenções: estimular a sindicalização; compor programas e ações que explicitem de fato a preocupação do Estado com aspectos da vida do trabalhador, situados para além da proteção das leis trabalhistas e do amparo da previdência social; controlar e disciplinar o tempo livre do operário; sistematizar uma experiência de educação não-formal do trabalhador e elevar seu nível cultural e recuperar a energia física e mental do operário de modo a prevenir os efeitos da fadiga.

Ocupava-se do desenvolvimento de atividades culturais, desportivas e de escotismo que se traduziam em acesso às bibliotecas, discotecas, teatros, cinemas, atividades esportivas, excursionistas. Cabe ressaltar, que essas ações, ao mesmo tempo em que contribuíam para a promoção da paz/controle social e para diluição dos possíveis conflitos promoviam o acesso às experiências culturais da população economicamente desfavorável (GOMES, 2003).

É plausível afirmar que as ações públicas de lazer fomentadas pelo Serviço de Recreação Operária também operavam com a mesma base meritocrática-particularista que norteava as demais políticas sociais, uma vez que eram ofertadas somente aos trabalhadores sindicalizados e às suas famílias. Ademais, essa política ficou restrita, inicialmente, ao Distrito Federal (Rio de Janeiro) e sua abrangência era pequena e não atingia um número significativo de trabalhadores distribuídos pelo Brasil.

Estando localizado no MTIC e sendo executado em parceria com os sindicatos, o SRO sintetizava operacionalmente aquilo que era interesse governamental na época. As ações de recreação tinham a preocupação com a restauração das condições psicofísicas para os dias de trabalho e com a construção de uma harmonia social por meio da convivência amistosa entre os cidadãos. Nas entrelinhas desses objetivos apresenta-se uma preocupação 
com a produção e com o trabalho e não com o lazer. Esse último torna-se somente um instrumento para melhorar o rendimento do operariado contribuindo para não dispersá-lo diante dos vícios e das condutas socialmente inaceitáveis. No que se refere à bandeira da paz social, aclamada nesse período, o que se observa era a instrumentalização do lazer com vistas ao consequente esquivo dos conflitos políticos abafados pelo regime ditatorial. No entanto, é importante destacar a fala de Rodrigues e Marcelino (2011) quando afirma que a gestão do órgão relacionado a SRO foi adquirindo novos contornos durante sua existência e subverteu à lógica inicialmente pensada.

Nesse período da história de conquista dos direitos sociais no Brasil não se tratou, no nível governamental, o lazer como direito de cidadania, mas sim como um instrumento para aliviar as tensões produzidas pelo mundo do trabalho industrial e como objeto de acomodação de conflitos políticos que por ventura pudessem emergir. Submeteu-se o lazer ao trabalho.

Sendo assim, concluímos que essa legislação da fase inicial de constituição do WelfareState no Brasil apresenta um significado ambíguo para o avanço da cidadania. A incorporação das massas se deu pela via das leis sociais e não pela ação sindical e política. Disso resulta o pensamento até hoje vigente que concebe os direitos sociais como favor e não como direito. A cidadania resultante é mais passiva e receptora do que ativa e reivindicativa.

O período democrático populista vigente entre 1945 e 1964 segue tendo como desafio administrar uma ordem relativamente democrática em contexto social e econômico regulado. Os arranjos clientelísticos e corporativistas promovidos para a eleição do segundo governo Vargas oferecem a política social como preço a ser pago (CARVALHO, 2015). 
De acordo com Draibe (1990, p. 8), o “[...] movimento de inovação legalinstitucional nos campos da saúde, assistência social e habitação popular expande o sistema de proteção social nos moldes e parâmetros definidos pelas inovações no período de 30/43". Acontece reafirmando o padrão seletivo no que se refere aos beneficiários das políticas (trabalhadores formais), heterogêneo no plano dos benefícios (de acordo com o IAP a que pertence) e fragmentário nos níveis institucional e financeiro (não são constituídos os sistemas nacionais). Em 1960 foi aprovada a Lei Orgânica da Previdência Social que uniformiza os benefícios e serviços a todos os trabalhadores regidos pela CLT sem, contudo unificá-la.

No âmbito das políticas de lazer, amparados pela aceitação do SRO pelo público operário, o governo federal propõe a ampliação do serviço para outros estados da federação uma vez que, a princípio, o SRO se manteve somente no Distrito Federal. Entretanto, diante do restrito orçamento, essa ampliação ficou comprometida se restringindo a eventos esporádicos e mantendo a mesma ótica de atuação promovida nos anos iniciais de sua implantação.

Ainda na conjuntura das políticas de proteção social implementadas, o lazer interpretado como tempo de não trabalho e as atividades recreativas que tinham a função de preencher esse tempo ocioso e promover uma harmonia social, compunham, como aponta Draibe (1990), o denso núcleo assistencial do Estado suscetível às práticas assistencialistas e clientelistas. 


\section{A Política de lazer no Período de Consolidação Institucional e de Reestruturação Conservadora (1964-1985)}

Entre os anos de 1966 a 1971 ocorre a consolidação do sistema de bem-estar social brasileiro sob o comando de um novo governo ditatorial. Acontece uma "[...] transformação da armação institucional e financeira do perfil da política social" com a organização efetiva de sistemas nacionais públicos ou estatalmente regulados na área de bens e serviços sociais básicos como a educação, assistência social, previdência e habitação. As políticas sociais assumem um caráter massificador com ampla cobertura e com tendências universalizantes (DRAIBE, 1993, p. 20).

No que tange as políticas de lazer, o movimento Esporte para Todos (EPT) instituído pelo Departamento de Educação Física e Desporto do Ministério da Educação e Cultura (MEC) e pelo Movimento Brasileiro de Alfabetização (MOBRAL) na década de 70 configurou-se como ação governamental na área. Considerando suas características, o esporte fomentado pelo EPT pode ser localizado como um conteúdo cultural do lazer sendo considerado, portanto como uma ação pública nessa área.

O EPT iniciou-se em 1977 com uma campanha para a implantação do desporto de massa no Brasil. O programa objetivava promover o esporte na perspectiva da educação permanente (termo utilizado nas propostas) e do desenvolvimento cultural. O discurso instituído nesse projeto era o da melhoria da saúde e o da humanização das cidades e seus habitantes, e afirmava os seguintes valores: o sentimento cívico e de vizinhança, a sociabilidade, o corpo esportivo. A intenção era a de produzir um "lazer verdadeiro" nas cidades e, para tanto, o movimento se concentrava nas proximidades da moradia e do local de trabalho dos participantes. 
Foram definidos dois tipos de programa: um nacional "constituído por promoções simultâneas de uma única atividade, num mesmo dia, período ou fim de semana" e um local com vistas a aumentar o número de praticantes dos esportes. Outra diretriz definida foi a realização de atividades de curta duração, orientadas para a participação massiva e para gerarem grande repercussão. Ficaram conhecidas como ruas de lazer e aconteciam nos finais de semana (CAVALCANTE, 1984, p. 17).

A campanha durou aproximadamente dois anos envolvendo 2.772 municípios, cerca de 9,7 milhões de pessoas e 10.458 voluntários lançando por fim uma publicação de nome Comunidade Esportiva que intencionava promover a troca de informações entre os organizadores do esporte popular, comunitário e de massa (COSTA, 1981).

Crítica do discurso produzido pelo EPT no Brasil, Cavalcante (1984) alerta para questões cruciais no cenário político da época.

O discurso sobre o Esporte para Todos tem sido predominantemente um discurso técnico-burocrático; um discurso que enfatiza o como fazer para expandir a prática do esporte; um discurso que não considera as relações do esporte com os aspectos econômicos, sociais e políticos da realidade na qual está inserido. No Brasil, esse discurso tem seguido a tendência internacional de mitificação e tecnificação (p. 20).

Analisando o EPT, através de documentos internacionais que o fundamentavam e de documentos nacionais que o criavam, Cavalcante (1984) apontou cinco conclusões. Para a autora, o programa mascarou a desigualdade social uma vez que diz desaparecer temporariamente (durante o jogo) as barreiras sociais de classe. Apresentou a recuperação psicossomática como lei, cultuou a forma física e a sociabilização e promoveu a "pseudo" igualdade de oportunidades e o desenvolvimento de potencialidades como dogmas. Ressalta ainda que o programa prolongou a ação técnica sobre o indivíduo para além do 
trabalho tornando-o adaptável às exigências industriais e instrumento de reprodução cultural. Por fim, o EPT “[...] está a serviço da despolitização da massa à medida que afasta o indivíduo da sua realidade social para cultivá-lo num espaço esportivo, abstrato, onde se exercita a obediência e a disciplina" (p. 108).

Uma tese proposta por Lenhardt e Offe $(1984$, p. 15) defende a premissa de que “[...] a política social é a forma pela qual o Estado tenta resolver o problema da transformação duradoura de trabalho não assalariado em trabalho assalariado". A industrialização desorganiza as condições de utilização da força de trabalho dominante na época de sua instituição e para reorganizá-la segundo os moldes do novo modelo de produção é necessária a ação imperativa do Estado. Para isso, é fundamental que os novos trabalhadores tenham motivos culturais para se transformarem em assalariados, é necessário definir quem pode e quem não pode tornar-se trabalhador e é indispensável que haja uma correspondência quantitativa entre demanda e disponibilidade para o trabalho.

No que se refere ao EPT poucas são as alterações ideológicas quando comparado ao SRO. A política governamental delineada pelo EPT também atuou tendo em vista um modelo cultural de cidadão almejado. O discurso da igualdade de oportunidades promovida pelo esporte (instrumento cultural) gerava um imaginário de harmonia social e mascarava a desigualdade. Era preciso que todos se empenhassem para a obtenção da meta do crescimento econômico e não se atentasse para a questão da distribuição - para que redistribuir se todos são iguais?

Quando utilizamos, para título de exemplificação, o modelo de política pública desenvolvida, por meio do SRO e do EPT não nos furtamos em considerar a capacidade e as possibilidades de resignificação que os usuários desses serviços poderiam imprimir a ele. 
Entretanto, o que interessava era a forma de concepção de políticas públicas, com todas as especificidades de seus respectivos tempos históricos, que se construía para o esporte e o lazer. Defendemos a idéia de que características marcantes que configuram as políticas desse setor específico são retrato da constituição das políticas sociais como um todo. Sendo assim, se pensarmos na constituição do Estado Social no Brasil não há como negar traços de clientelismo, patrimonialismo e populismo.

A exclusão da participação social e política nos processos de decisão é uma característica dessa fase assim como o autofinanciamento do investimento social que submeteu o gasto social a critérios econômicos e financeiros de rentabilidade privada. A privatização incorpora a idéia de que o cidadão tem de pagar pelo que recebe desembocando na diminuição da participação relativa do Estado nos setores sociais e o correlato crescimento da participação do setor privado na oferta desses serviços.

Por fim, o uso clientelista da máquina pública que se expressa pela política dos favores fomentada durante o regime militar como uma forma de sustentação do mesmo. Dessa forma, o Estado de Bem-Estar Social brasileiro em sua fase de implantação e consolidação apresenta suas especificidades que em comparação com os países industrializados permite dizer que o mesmo faz uso das políticas sociais como “[...] instrumento de legitimação da ordem política e social fornecendo mão-de-obra assalariada para a indústria" (MEDEIROS, 2001, p. 21).

Draibe (1993, p. 30) avaliando as bases sobre as quais foi constituído o Welfare State no Brasil em comparação com os países industrializados afirma que nesses últimos as políticas sociais de bem-estar surgem em situação de pleno emprego acompanhada por um aumento no salário real e uma consequente elevação nos níveis de vida da maioria da 
população. No Brasil a situação é diferente:

[...] a base contributiva (salário) é relativamente estreita e consequentemente a qualidade dos serviços é afetada e os benefícios são insuficientes para as finalidades a que se destinam, a política tende a se assistencializar e os programas voltados para o combate à miséria ficam sobrecarregados por terem que enfrentar as carências de praticamente um terço da população, mesmo os empregados necessitam da assistência do Estado para assegurar uma vida digna e nesse quadro, os recursos tornamse parcos para suportar as tarefas ampliadas da política assistencial e para complementar os benefícios de base contributiva.

Em complementação, as políticas sociais instituídas sobre bases meritocráticas,

como no Brasil, “[...] reproduzem o sistema de desigualdade preexistente na sociedade sendo escassos seus aspectos redistributivos" (DRAIBE, 1990, p. 10). A inexistência de mínimos sociais independentes da ocupação funcional fragilizam as políticas sociais como mecanismos corretores.

Ressalta-se que no Brasil existe um agravante: o fato do Estado, ter se antecipado aos conflitos sociais ocasionados pela exploração do trabalho utilizando as políticas sociais como moeda de troca a favor da suspensão dos direitos políticos. Se nos países industrializados a conquista dos direitos sociais foi consequência da árdua luta travada entre operários e patrões, no Brasil (de industrialização tardia) embora essa efervescência tenha ocorrido ela foi mitigada antecipadamente pelo Estado autoritário. É como se o mesmo cumprisse uma dupla função em favor dos interesses do capital deslegitimando o conflito que negociaria a tênue linha do compromisso de classe.

\section{As Políticas de Lazer na Reestruturação Progressista (Após 1985)}

Culmina-se, em todo mundo, a crise do Estado de Bem-Estar Social sentida a partir da década de 70 com o colapso do petróleo. Para Abrucio (1997,p.7) apresentava três 
dimensões interligadas: econômica, social e administrativa. A dimensão econômica se caracterizava pela intervenção do Estado na economia "[...] procurando garantir o pleno emprego e atuar em setores considerados estratégicos como telecomunicações e petróleo". No que se refere à dimensão social, objetivava-se garantir as necessidades básicas da população por meio da execução de políticas públicas na área social (educação, saúde, previdência social, habitação). Por fim, havia a dimensão de funcionamento do Estado que seguindo os moldes apresentados pelo modelo burocrático weberiano prezava a impessoalidade, a neutralidade e a racionalidade da administração estatal.

O fato é que a crise econômica acendida principalmente pelas duas crises do petróleo (1973 e 1979) gerou um período recessivo na década de 80 que afetou diretamente os Estados. Estes se viram diante de uma demanda social em detrimento aos baixos recursos financeiros necessários para solucioná-la. "Estava em xeque o consenso social que sustentara o Welfare State" (ABRUCIO, 1997, p.11) e nesse cenário de crise mundial emergiram os neoliberais que fortalecidos pelas eleições de Reagan nos EUA e Thatcher na Grã Bretanha defendiam a premissa do Estado mínimo com um discurso que intitulava o modelo weberiano como ineficiente, pouco flexível e clientelista. As diretrizes do Estado mínimo pressionam, internacionalmente, pela diminuição do tamanho do Estado sugerindo uma nova lógica de gestão pública. Recomendam que a ação pública seja direcionada para os grupos sociais impossibilitados de conseguir no mercado o provimento dos serviços estimulando a privatização. Algumas tendências surgem: descentralização políticoadministrativa como estímulo a democratização e à contenção de custos; participação popular no processo de constituição de políticas públicas e redução do Estado com estímulo à privatização e ao terceiro setor. 
No Brasil, aumentava a demanda pelo resgate da dívida social que suscitava uma revisão do padrão de financiamento das políticas sociais, a implantação de critérios mais justos de equidade e a reforma da máquina estatal. Criticava-se o caráter burocrático, privatista, centralizado, excludente e ineficaz de gestão das políticas sociais e sugeria a participação popular, a transparência nos processos públicos e a descentralização.

Concomitantemente à elaboração de planos emergenciais de combate à fome, ao desemprego e a miséria foram criadas comissões de proposição com o objetivo de sugerir princípios para a reformulação do padrão do Estado Social brasileiro. Estas comissões eram compostas por técnicos governamentais, acadêmicos e membros da sociedade civil. Foram elencados como princípios para a reforma a descentralização, a participação popular, a garantia do direito social em detrimento ao assistencialismo, clientelismo e tutela culminando na Constituição de 1988 (DRAIBE, 1990).

Contudo, como era de se esperar, a fase de implementação das diretrizes constitucionais que deveriam acontecer a partir dos anos 90 tinha como conjuntura os reflexos da crise fiscal que eram sentidos por aqui. Internacionalmente difundia-se uma nova agenda para o Estado que sugeria redefinir o balanço entre as esferas públicas e privadas, via redução do Estado na oferta de bens e serviços de natureza social. A esfera pública deveria se organizar tendo em vista os grupos sociais impossibilitados de conseguir no mercado o provimento dos serviços. O eixo analítico de problematização das políticas públicas se desloca no sentido da redefinição do papel do Estado e da legitimidade do mesmo e não mais sobre a forma e conteúdo da intervenção pública.

Sendo assim, configuraram como tendências segundo Draibe (1990):

1. Político-institucionais: descentralização político-administrativa, com fortes vertentes de 
municipalização associando contraditoriamente objetivos de democratização e de diminuição de gasto.

2. Sociabilidade das políticas sociais: elevação do grau de participação popular em processos de decisão, elaboração e implementação de políticas - florescimentos dos associativismos.

3. Relação Estado, setor lucrativo e setor não lucrativo na produção de serviços sociais: participação dos beneficiários, de associações comunitárias, $\mathrm{ONG}^{\prime} \mathrm{s}$ e movimento de redução do setor público com privatização em sentido estrito - movimento do Estado para o setor privado - e em sentido amplo - reforço do não estatal, do privado não lucrativo, de setores autônomos, do terceiro setor. O desemprego estrutural de longa duração, a piora na distribuição de renda, o aumento e diversificação da pobreza e a redução dos recursos fiscais exerceram pressão sobre o sistema de proteção social constituindo-se o cenário da década de 90. Os reflexos da crise do Estado eram visivelmente identificados e nesse contexto os governos viviam o dilema entre a nova política econômica e a política de proteção social. Na América Latina como um todo foi feita a opção pelo ajustamento fiscal e pelas reformas comerciais e patrimoniais pró-mercado. Ocorreram privatizações de serviços sociais, quedas do gasto social e redução do grau de proteção social (DRAIBE, 1998).

Um novo ciclo de reformas é implementado e apóia-se, segundo Draibe (1998), sobre as premissas de que os serviços sociais básicos, de caráter universal e de responsabilidade pública, envolvem a previdência social, a saúde, a educação, a assistência social, a habitação e o saneamento. Os programas de trabalho, emprego e renda visam gerar novas oportunidades de trabalho, qualificar e proteger o trabalhador e por fim, tornam-se 
programas prioritários aqueles que promovem o combate à pobreza por meio da redução da mortalidade infantil, da educação infantil e ensino fundamental, da geração de ocupação e renda, da qualificação profissional, da melhoria das condições de alimentação dos escolares e famílias pobres e das condições de moradia e saneamento básico e do fortalecimento da agricultura familiar.

Ainda nesse periodo, enfatizou-se os programas de transferência de renda que, liderado pelo Programa Comunidade Solidária, direcionavam suas ações para os segmentos mais carentes regidos pelos critérios de território e de renda. As Organizações não Governamentais (ONG) passaram a ser reconhecidas como legítimas interlocutoras da sociedade no que tange a formulação da política social. O discurso do Estado mínimo é propagado, difundido e reproduzido por diversos veículos mesmo que diretamente não tenhamos nos atentado para ele. Em alguns casos, as ONG's atuam como um coletivo de representantes da sociedade civil que comungam de uma mesma concepção de vida e daí questionam das ações do Estado, como o Greenpeace. Em outros casos, talvez os mais recorrentes atualmente, as mesmas são formatadas dentro dos gabinetes de governo com a função de promover ou viabilizar ações do próprio Estado "terceirizando" suas responsabilidades.

O centro da política se desloca da redistribuição da riqueza para o tratamento compensatório de seus efeitos, ou seja, despolitização promovendo a passagem da universalidade inclusiva proposta pela Constituição para a gestão estratégica da pobreza. Os programas tornam-se mitigadores setorializados e focalizados na pobreza.

As políticas sociais tendem assim a abarcar segmentos populacionais em situação de maior risco e vulnerabilidade social. A pobreza e desigualdade configuram-se como 
questões de solidariedade social formando a base de um sistema misto de proteção que concilia iniciativas do Estado e do terceiro setor. Promove-se assim a refilantropização da questão social e despolitização da política social (DRAIBE, 1998).

Nesse caminho de ampliação e reconfiguração dos direitos o lazer é estabelecido pela Constituição de 1988 como um direito social merecendo e se tornando obrigatoriamente um assunto a ser tratado pelo Estado por meio das políticas públicas. A partir da constituição, o lazer passa a ser assegurado em outras leis e documentos nas esferas federais, estaduais e municipais. Um passo importante para a democratização do esporte e lazer é concretizado com a criação do Ministério do Esporte (ME), pela Medida Provisória $n^{\circ} 103$, de $1^{\circ}$ de janeiro de $2003^{3}$. Sua missão, segundo os documentos oficiais, é “[...] formular e implementar políticas públicas inclusivas e de afirmação do esporte e do lazer como direitos sociais dos cidadãos, colaborando para o desenvolvimento nacional e humano"4.

A Constituição Federal de 1988 inaugura uma nova maneira de conceber o lazer que, mesmo estabelecendo uma relação direta com o trabalho, passa a ser reconhecido como uma riqueza cultural que deve ser garantida a todos os cidadãos como premissa de qualidade de vida. Contudo, apesar do avanço da produção teórica sobre o assunto, ainda há que se investigar as circunstâncias, as definições e os interesses que permearam a inclusão desse tema na agenda.

Diante da contradição imposta pela crise do Welfare State e pela ascensão neoliberal

\footnotetext{
${ }^{3}$ Disponível em: http://www.planalto.gov.br/ccivil_03/mpv/antigas_2003/103.htm Acesso em: 21 out. 2013.

${ }^{4}$ Disponível em: http://www.esporte.gov.br/conferencianacional/arquivos/teseFinal.pdf Acesso em: 21 out. 2013.
} 
o percurso traçado, em muitos casos, não é garantidor do direito ao lazer. Dessa forma, as abordagens compensatórias, moralistas, utilitaristas e românticas, utilizadas nas décadas de 30 e 70, se vestem com uma nova roupagem sugerindo que as ações de lazer afastam as crianças da rua e da marginalidade ocupando seu tempo livre.

Questionando a perspectiva de interpretação mercadológica do direito ao lazer Mascarenhas (2005, p. 155) reflete sobre a privatização dos direitos sociais no Brasil frente às investidas neoliberais. Utilizando dois termos cunhados de significado: mercolazer e lazerania, o autor afirma que lazer "[...] passa a subordinar-se diretamente a produção e reprodução do capital, sucumbindo, de modo tendencial e dominante, à forma mercadoria". Esse fato fundamenta o autor a nomear aqueles cidadãos que não tem acesso ao mercolazer como os "sem lazer". Define ainda o que vem chamando de política de lazerania que consiste "[...] em converter a maior quantidade possível de espaços, equipamentos, projetos e programas de lazer em verdadeiras casamatas da vontade coletiva” (p. 170).

Refletindo sobre as ponderações desse autor corroboramos com a idéia de que, atualmente, o lazer tem se manifestado de modo predominante sob a forma mercadoria. No entanto, mesmo considerando o tempo disponível para a vivência do lazer cada vez mais restrito por uma imposição do tempo do trabalho e por questões financeiras, questionamos o termo "sem lazer". Se estamos, em busca de outro lazer que problematiza e escapa da forma mercadoria não há como desconsiderar a vivência e a resignificação cotidiana dos sujeitos que teoricamente estejam à margem do mercolazer. Acreditamos que a premissa da lazerania seja o reconhecimento da alteridade dos sujeitos independentemente da classe social, faixa etária, etnia ou gênero.

O fato é que é inegável o avanço do neoliberalismo a partir da década de 90 assim 
como o é a crise de legitimidade que passa o Estado Social estimulando seu questionamento. No que tange ao lazer, existem políticas públicas acontecendo desde a época de 30, exemplo disso foram apresentados com o SRO e o EPT. Entretanto mesmo que existam políticas públicas de lazer elas não necessariamente almejam, em primeira linha, o direito ao lazer. Objetiva mitigar os efeitos do trabalho, promover a paz social, minimizar os conflitos políticos, ocupar o tempo "ocioso", diminuir criminalidade, consumo de drogas, manter vivo. O lazer pode se tornar instrumento facilitador para todos esses objetivos, mas a pergunta acaba não sendo retórica e sim necessária. Parafraseando Telles (2006) direito ao lazer: afinal, do que se trata?

Para Menicucci (2006) a luta pela garantia desse direito

[...] obriga desmontar esperanças em um ativismo estatal isolado da construção social de um ideário relativo ao lazer, processo que envolve uma definição de lazer e de políticas de lazer, dos princípios e diretrizes a orientar essa política, dos conteúdos principais e das formas de sua implementação (p. 141).

É necessário a ação de um conjunto de atores sociais, que comungando de uma mesma concepção buscam incluir o tema na agenda pública. Parafraseando Menicucci (2006, p. 145), se “[...] o referencial de uma política é a imagem cognitiva que se tem da realidade e é dessa percepção que emergem as soluções ou propostas de ação”, então, falar em direito ao lazer no Brasil ainda significa reproduzir seu caráter utilitário, moralista e salvacionista. Seria ingênuo afirmar que os interesses que alimentam tal versão são despropositados e descompromissados. Talvez devêssemos nos atentar para a imagem cognitiva que ainda reproduzimos e para o fato de que o questionamento dessa imagem só será escutado quando pararmos de acreditar no ativismo estatal isolado e reunirmos em uma comunidade epistêmica capaz de divulgar outros valores. Acreditamos ainda que isso será 
possível quando resgatarmos o sentido da palavra e da ação política.

É relevante considerar as ações desenvolvidas no âmbito federal que, crivadas de questionamentos, tentam inaugurar uma nova forma de pensar as políticas públicas de esporte e lazer. A Política Nacional do Esporte, criada a partir da I Conferência Nacional do Esporte (BRASIL, 2004), orienta as ações da temática e destaca as três linhas de atuação do Ministério: o esporte educacional, o esporte de rendimento e o esporte recreativo ou de lazer. Se pensarmos no caráter hegemônico do alto rendimento podemos interpretar essa iniciativa como uma tentativa de reconhecer outras manifestações esportivas, necessária para a democratização desse direito social.

É significante ainda o modelo do Programa Esporte e Lazer da Cidade (PELC) implementado pela Secretaria Nacional de Esporte, Educação, Lazer e Inclusão Social (SNELIS) do Ministério do Esporte que estabelece princípios norteadores como a intergeracionalidade, a participação popular entre outros até então incipientes na área. Promove e incentiva a produção de conhecimento, através da Rede CEDES, almejando a construção de um rede de atores capazes de formar outra concepção de política pública para $\mathrm{a}$ área.

Vieira et al. (2011) afirmam que o PELC tem como proposta construir uma política de Estado que considere o lazer e o esporte de participação como direitos sociais a serem geridos pelos governos de forma teórico-prática, tratando esses elementos como possuidores de conteúdos próprios e amplos, e como elementos de cidadania. Segundo os autores, esta proposição, em princípio, tende a auxiliar no estabelecimento do esporte e do lazer como objeto de política de Estado. No entanto, por não ser uma das prioridades governamentais, esta possibilidade torna-se pouco provável, tendo em vista que a 
construção de políticas de Estado irá depender de inter-relações políticas e arranjos institucionais. Por isso concordamos com Vieira et al. (2011) quando afirmam ser necessário:

[...] o desenvolvimento de uma governabilidade que permita maior visibilidade e introdução das temáticas lazer e esporte de participação na agenda política brasileira. É fundamental, ainda, que se busque maior amplitude do programa, o que pode ser facilitado pelo aprimoramento da governança local por meio de suas propostas de formação continuada ( $\mathrm{p}$. $68)$.

Além disso, concordamos com Castellani Filho (2007) quando aponta que a identificação no título do programa das expressões esporte e lazer foi proposital, pois buscava-se pontuar que os termos se constituíam em conceitos distintos, mas com possibilidades de inter-relações. Isso porque o esporte, em sua dimensão recreativa que se dissocia da busca pelo rendimento, encontra no lazer uma possibilidade concreta de expressão. Portanto, a ideia era reforçar que, no tempo e espaço de lazer, o esporte, sem o sentido performático, se apresenta como uma possibilidade de ser vivenciado por todos os que o procuram, seja na forma de prática ou de fruição do espetáculo.

Entretanto, é necessário ressaltar que, atualmente, parte dos projetos que pleiteiam recursos para efetivação do PELC nos municípios, acontece por meio de emendas parlamentares e subsídios de outros ministérios. Esse fato pode indicar que o lazer não vem sendo tratado de fato como um direito social atrelado a sua garantia e sim às necessidades de outros direitos.

\section{Considerações Finais}

Acreditamos que conhecer esse cenário de constituição e consolidação do Estado 
de bem estar social no Brasil com todas as suas peculiaridades, especificidades e dilemas serve como subsídio para interpretar a ação pública no campo de lazer. Nessa trajetória, é importante destacar que ainda temos muito a caminhar quando tratamos da garantia do lazer como direito social, por meio da efetivação de políticas sociais.

Na trajetória apresentada nesse texto, foi possível identificar a submissão do lazer a políticas de diferentes áreas, tais como: trabalho, educação, saúde, no entanto, para a garantia desse direito é preciso que o lazer esteja associado, de maneira horizontal, a um conjunto de políticas que busquem a garantia da cidadania.

\section{REFERÊNCIAS}

ABRÚCIO, F. L. O impacto do modelo gerencial na AdministraçãoPública. Cadernos ENAP, Brasília, 1997.

BEHRING, Elaine Rossetti e BOSCHETTI, Ivanete. Política Social: fundamentos e história. 3. ed. São Paulo: Cortez, 2007.

BRASIL. Constituição dos Estados Unidos do Brasil. Brasil: Rio de Janeiro, 1937.

I Conferência Nacional do Esporte: Esporte, Lazer e Desenvolvimento Humano. Brasília: Ministério do Esporte, 2004.

BRÊTAS, A. Nem só de pão vive o homem: criação e funcionamento do Serviço de Recreação Operária (1943-1945). Rio de Janeiro: Apicuri, 2010.

CARVAlHO, J. M. de. Cidadania no Brasil: o longo caminho. 19. ed. Rio de Janeiro: Civilização Brasileira, 2015.

CASTELLANI FILHO, L. (Org.). Gestão pública e política de lazer: a formação de agentes sociais. Campinas: Autores Associados. 2007.

CAVALCANTI, K. B. Esporte para todos: um discurso ideológico. São Paulo: Ibrasa, 1984.

COSTA, L. P. da. Teoria e Prática do Esporte Comunitário e de Massa. Rio de Janeiro: Palestra, 1981. 
COUTINHO, Carlos Nelson. Representação de interesses, formulação de políticas e hegemonia. In: TEIXEIRA, Sônia F. (Org.). Reforma sanitária, em busca de uma teoria. São Paulo: Abrasco/Cortez, 1989.

DRAIBE, S. M. O Welfare State no Brasil: características e perspectivas.Cadernos de pesquisa, n. 08. Campinas, NEPP/UNICAMP, 1993.

. O Sistema Brasileiro de Proteção Social: o legado desenvolvimentista e a agenda recente de reformas. Cadernos de pesquisa, n. 32. Campinas, NEPP/UNICAMP, 1998.

- As políticas sociais brasileiras: diagnósticos e perspectivas. In: IPEA/IPLAN (Org.). Para a década de 90: diagnóstico e perspectivas. Brasília, 1990.

ESPING-ANDERSEN, G. As Três Economias Políticas do Welfare State. Revista Lua Nova, n 24, setembro, 1991.

GOMES, C L. Significados de Recreação e Lazer no Brasil: reflexões a partir da análise de experiências institucionais (1926 - 1964). Tese (doutorado em Educação) - Faculdade de Educação, UFMG, Belo Horizonte, 2003.

LENDHARDT, G. e OFFE, C. Força de Trabalho e Poder da Sociedade. In: OFFE, Claus (Org.). Problemas Estruturais do Estado capitalista. Rio de Janeiro: Tempo Brasileiro, 1984.

MASCARENHAS, F. Entre o Ócio e o Negócio: teses acerca da anatomia do lazer. Tese (doutorado em EducaçãoFísica) - Faculdade de EducaçãoFísica, Unicamp, Campinas, 2005.

MEDEIROS, M. A Trajetória do WelfareState no Brasil: papel redistributivo das políticas sociais dos anos 1930 aos anos 1990. IPEA. Brasília, 2001.

MENICUCCI, T. Políticas Públicas de Lazer: questões analíticas e desafios políticos. In: ISAYAMA, H. e LINHAleS, M. A. (Org.). Sobre Lazer e Política: maneiras de ver, maneiras de fazer. Belo Horizonte: Editora da UFMG, 2006.

REIS, F. W. Mercado e Utopia: teoria política e sociedade brasileira. São Paulo: Editora da Universidade de São Paulo, 2000.

RODRIGUES, R. P. e MARCELLINO, N. C. O lazer nas políticas públicas participativas de Porto Alegre: estudo das gestões municipais de 1994 a 2004. Licere, v. 14, n.3, 2011.

SANTOS, W. G. dos. Cidadania e justiça: a política social na ordem brasileira. 2. ed. Rio de Janeiro: Campus, 1994.

A Trágica Condição da política social. In: ABRANCHES, Sérgio Henrique et al. Política Social e Combate à Pobreza. Rio de Janeiro: Zahar, 1987. 
SUSSEKIND, A. Trabalho e Recreação: fundamentos, organização e realizações do Serviço de Recreação Operária. Rio de Janeiro: Ministério do Trabalho Indústria e Comércio, 1946.

TELLES, V. da S. Direitos Sociais: afinal do que se trata? 2. ed. Belo Horizonte: Editora da UFMG, 2006.

VIEIRA, L. H. S.; Silveira, S. F. R.; Ferreira, M. A. M.; Teixeira, K. M. D. Estudos sobre a Gestão do Programa Esporte e Lazer da Cidade. Brasília: Gráfica e Editora Ideal, 2011.

ZAULI, E. M. Gastos Sociais, Pobreza e Desigualdade de Renda no Brasil. Pensar BH. Política Social. set, 2005.

\section{Endereço dos Autores:}

Tarcila Bretas Lopes

Secretaria Municipal de Esporte e Lazer

Prefeitura Municipal de Belo Horizonte

Av. Getúlio Vargas 1245 - Funcionários

Belo Horizonte - MG - 30.112-021

Endereço Eletrônico: tarcilabretas@hotmail.com

Dalva de Cássia S. dos Santos

Av. Chaco 1857 apt. $801-$ Marco

Belém - PA - 66.093-541

Endereço Eletrônico: dalssia@hotmail.com

Hélder Ferreira Isayama

EEFFTO/UFMG

Av. Antonio Carlos 6627 - Pampulha

Belo Horizonte - MG - 31.270-901

Endereço Eletrônico: helderisayama@yahoo.com.br 